\title{
Solution for Hemofiltration Dosage Form
}

National Cancer Institute

\section{Source}

National Cancer Institute. Solution for Hemofiltration Dosage Form. NCI Thesaurus.

Code C149909.

Liquid sterile preparation consisting of an aqueous solution containing electrolytes with a concentration close to the electrolytic composition of plasma, intended for parenteral use in hemofiltration. Glucose may be included. 